\title{
BMJ Open How do patients respond to safety problems in ambulatory care? Results of a retrospective cross-sectional telephone survey
}

\author{
Svenja Seufert (D) , ${ }^{1}$ Werner de Cruppé, ${ }^{1}$ Michaela Assheuer, ${ }^{1}$ Johannes Leinert, ${ }^{2}$ \\ Max Geraedts
}

To cite: Seufert S, de Cruppé W, Assheuer M, et al. How do patients respond to safety problems in ambulatory care? Results of a retrospective cross-sectional telephone survey. BMJ Open 2021;11:e052973. doi:10.1136/ bmjopen-2021-052973

- Prepublication history and additional supplemental material for this paper are available online. To view these files, please visit the journal online (http://dx.doi.org/10.1136/ bmjopen-2021-052973)

Received 01 May 2021 Accepted 18 October 2021

Check for updates

(C) Author(s) (or their employer(s)) 2021. Re-use permitted under CC BY-NC. No commercial re-use. See rights and permissions. Published by BMJ.

${ }^{1}$ Institute for Health Services Research and Clinical Epidemiology, PhilippsUniversität Marburg, Marburg, Germany

${ }^{2}$ infas Institut fur angewandte Sozialwissenschaft GmbH, Bonn, Germany

Correspondence to

Max Geraedts;

geraedts@uni-marburg.de

\section{ABSTRACT}

Objectives Patients in German ambulatory care frequently report patient safety problems (PSP). It is unclear whether patients report PSP back to their general practitioner (GP) or specialist in charge. This study reports on how patients respond to experienced PSP.

Design Retrospective cross-sectional study.

Setting Computer-assisted telephone interviews (CATI) with randomly recruited citizens aged $\geq 40$ years in Germany.

Participants 10037 citizens $\geq 40$ years. About $52 \%$ of the interviewees were female, $38 \%$ were between 60 and 79 years old and about $47 \%$ reported that they were chronically ill. A total of 2589 PSPs was reported.

Primary and secondary measures/Results According to the respondents $(n=1422,77 \%, 95 \% \mathrm{Cl}: 74.7$ to 79.1$)$, $72 \%$ (95\% Cl: 70.2 to 73.7 ) of PSP were reported back to the GP in charge or to another GP/specialist. Further reactions were taken by $65 \%$ ( $95 \% \mathrm{Cl}$ : 62.5 to 67.5 ) of the interviewees: around $63 \%$ (95\% Cl: 62.5 to 66.2 ) of the reported PSP led to a loss of faith in the physician or to complaints. $\chi^{2}$ and binary logistic regression analyses show significant associations between the (a) reporting and (b) reaction behaviour and determinants like 'medical treatment area' ((a) $\chi^{2}=17.13, \mathrm{p}=0.009 /(\mathrm{b}) \chi^{2}=97.58$, $\mathrm{p}=0.000)$, 'PSP with/without harm' ((a) $\chi^{2}=111.84$, $\left.\mathrm{p}=0.000 /(\mathrm{b}) \chi^{2}=265.39, \mathrm{p}=0.000\right)$ and sociodemographic characteristics when respondents are aged between 40 and 59 years ((a) OR 2.57/(b) OR 2.60) or have chronic illnesses ((a) OR 2.16/(b) OR 2.14).

Conclusion The data suggest that PSPs are frequently reported back to the GP or specialist in charge and have a significant serious impact on the physician-patient relationship. Much could be learnt from the patient reporting and reacting behaviour to prevent PSPs in ambulatory care.

\section{INTRODUCTION}

With a 1-year incidence of $14.2 \%$, ambulatory care patients aged $\geq 40$ years in Germany frequently report self-experienced patient safety problems (PSP). ${ }^{1}$ Internationally, the state of research on the frequency of PSP in the ambulatory care sector is insufficient. According to a systematic literature review

\section{STRENGTHS AND LIMITATIONS OF THIS STUDY}

$\Rightarrow$ The study focuses for the first time on the reporting and further reaction behaviour of ambulatory care patients affected by patient safety problems (PSP) in Germany.

$\Rightarrow$ The study suggests that patients in ambulatory healthcare are able to report experienced or suspected PSP to their physicians in charge.

$\Rightarrow$ The large probability sample $(\mathrm{n}=10037$ citizens $\geq 40$ years of age) allows for statistical extrapolation and ensures a low random variation or results, that is, a high degree of certainty regarding the coping strategies used by patients who experienced safety problems in ambulatory care.

$\Rightarrow$ No conclusions can be drawn whether the reporting and further reaction behaviour could make a positive contribution to the future avoidance or reduction of PSP.

$\Rightarrow$ The response rate of the target group was $12.4 \%$, which is in the lower range that could be expected; furthermore, a selective willingness to participate in the study cannot be ruled out.

by Panesar et al 1-24 patient safety incidents (PSI) per 100000 ambulatory consultations can be expected. ${ }^{2}$ Phenomenologically, the term PSP includes both 'error' and 'PSI'. An error is understood to be the failure to carry out a planned action as intended or the application of an incorrect plan. ${ }^{3}$ A PSI is an event or circumstance that could have led or did lead to unnecessary harm to patients. ${ }^{3}$

In everyday medical practice, PSP are not completely avoidable and will occur occasionally despite all measures taken to prevent them. ${ }^{4}$ In this context, PSP both pose a direct risk to the health and well-being of patients, and can also negatively influence the physician-patient relationship to a considerable extent. ${ }^{5}$ Since patients leave the physician's office immediately after receiving ambulatory treatment and dissatisfaction is the strongest 
factor for changing physicians, medical service providers can only insufficiently determine PSP and its social impact on patients. Thus, it is unclear how ambulatory care patients deal with PSP and whether they report experienced PSP back to their physician in charge or to another physician, or if they contact their insurance companies or seek legal counsel after experiencing a PSP directly.

To date, few studies have addressed the reporting and reaction behaviours of patients who experienced PSP in ambulatory care settings, and some studies have focused on healthcare professionals' experiences with patient responses. In a 2010 nationwide survey of general practitioners (GPs) and ambulatory care specialists in Germany on the topic of quality management and patient safety in medical practices, $62 \%$ of physicians surveyed reported never being confronted with allegations of errors, only $28 \%$ of physicians reported dealing with dissatisfied patients due to errors once a year, and only $10 \%$ more frequently than once a year; $73 \%$ of the surveyed patients with experienced PSP first sought a conversation with the GP directly, while $20 \%$ of the patients consulted a lawyer directly without seeking clarification from the care provider first. According to the respondents, $15 \%$ of the patients reacted with defamation. Additionally, the participating physicians stated in the free comments that their patients had changed the physician without explanation or simply stayed away. ${ }^{6}$ In international studies, participating physicians reported that around $12 \%$ of errors $(\mathrm{n}=330)$ resulted in emotional distress or loss of faith by affected patients. ${ }^{7}$ In the study conducted by Ushie $e t$ $a l^{8}$ around $99 \%$ of the Nigerian patients surveyed stated that they would react with negative feelings, expressed in (strong) anger and disappointment, in the case of a treatment error. Only $4 \%$ of the respondents would forgive the medical provider completely, while around $2 \%$ of them would take actions depending on the error. Thus, around $36 \%$ would sue the hospital or the service provider for financial compensation and/or would like the person who committed the error to be suspended (34\%). In the study by Giardina et at roughly $66 \%$ of 184 US patients treated and surveyed in both inpatient and outpatient settings stated that they or their families reported experienced adverse events back to the institution where the incident occurred (45\%) or subsequently contacted another authorised health agency (19\%). In only 6\% were the patients concerns satisfied with the response of the institutions contacted. Nevertheless, studies suggest that patients are motivated to report incidents they have experienced in order to prevent a similar event from happening to other patients. ${ }^{10}$ Mazor $e t a l^{11}$ conducted in-depth telephone interviews with cancer patients who believed that they experienced a preventable, harmful event during their initial cancer diagnosis or subsequent care. Out of 78 completed interviews, it was found that just a few clinicians (6\%) initiated discussions surrounding the problematic events, while the patient or family members initiated the discussion more frequently $(27 \%)$. However, at least $68 \%$ of patients reported discussing the presumed event with someone in the healthcare system than the person they considered responsible. Only a few affected patients (13\%) formally reported their problematic events in writing, spoke with someone in administration or completed satisfaction surveys. Almost all patients reported making changes in their healthcare-related behaviour, for instance about $54 \%$ of cancer patients were more likely to seek a second opinion $(42 \%)$ or change physicians (12\%). A similar distribution was found in the cross-sectional study by Kistler $e \mathrm{al}^{12}$ and in the telephone survey conducted by the American Medical Association (AMA) $)^{13}$ in 1977: roughly $14 \%$ of the patients surveyed by Kistler et al $(\mathrm{n}=1697)$ and $10 \%$ of those surveyed by the AMA ( $n=639)$ stated that they had changed their physician in charge due to an error.

Due to the fact that there have been no systematically recorded figures on the responding behaviour of ambulatory patients in dealing with experienced PSP in Germany, the present study focuses for the first time on the reporting and further response behaviour of affected patients. In addition to descriptive recording, it is examined whether the reporting and reaction behaviour differs according to the treatment area and the type of PSP, the specialist group, PSP with and without harm, the type of harm as well as the severity, the recovery time and the additional treatment. In addition, the relationship between the reporting and reaction behaviour and the sociodemographic characteristics of affected patients was investigated.

\section{METHODS}

The study data originate from the retrospective study 'PAV-Patient Safety in Ambulatory Care' (F-KZ: 01VSF16015) funded by the Innovation Committee at the Federal Joint Committee (G-BA) and based on survey data collected by means of computer-assisted telephone interviews (CATI) on a representative population sample ( $\mathrm{n}=10037)$ of adults aged $\geq 40$ years. We followed the Strengthening the Reporting of Observational Studies in Epidemiology checklist for reporting observational studies (see online supplemental file 1). ${ }^{14}$

\section{Questionnaire and setting}

The CATI survey was based on a newly developed questionnaire (PSP-AMB), ${ }^{15}$ which was developed by means of a systematic literature review and qualitative interviews with physicians and patients $(n=20)$ of the ambulatory care in Germany. In the first section, PSP-AMB records a total of 32 types of PSP of the last 12 months in seven treatment areas and, for each confirmed PSP, detailed questions on the specialist group involved, the damage associated with the PSP, the reporting and further reaction behaviour as well as the sociodemographics of affected patients (online supplemental e-Box 1). In order to minimise cognitive stress and memory bias, complex filters ensured the interviewees were just asked the questions relevant to them. After completing both qualitative $(n=20)$ and 
quantitative $(n=110)$ pretests, a total of 10037 people $\geq 40$ years of age were interviewed nationwide between May and October 2018 by using a random sample of listed and permuted landline and mobile phone numbers (70:30 distribution). To ensure that even hard-to-reach target persons could be won over for an interview, the telephone numbers were contacted continuously throughout the entire field period from Monday to Friday between 4:00 pm and 9:00 pm and on Saturdays between 10:00 am and 6:00 pm. In order to reach as many prospective participants as possible, both the days of the week and the times of day were permanently varied for the contact attempts. If desired, participants could be called again for the interview on a different date (including mornings, early afternoons or weekends) or at a different telephone number. In addition, if necessary, interviews that had already begun could be interrupted and continued at a later time.

In multiple-person households, the adult with the most recent birthday was the target person. Out of almost 700000 telephone numbers generated, around 81000 could be identified as belonging to the target group; of these, around 65000 could be interviewed during the field time. Approximately $84 \%$ refused to participate. Just a few interviews were aborted (150) or could not be evaluated (5), so that in the end, a participation rate of $12.4 \%$ was achieved (10 037/81 108). The variables gender, age group, household size, school education, employment status, nationality, federal state and municipality size classes were used as weighting factors.

\section{Sample}

For reasons of research economics, the actual sample realised $(n=10037)$ refers only to the population of $\geq 40$-year-old citizens in Germany, since these are expected to have a higher probability of illness and physician visits than younger citizens (2017: 22.5 million men; 24.7 million women; $57 \%$ of the total population). The sample largely corresponds to the participants of the population survey conducted by the Robert Koch-Institute (RKI) in Germany as part of the 2014 health reporting (GEDA 14). ${ }^{116}$ Around $88 \%$ of participants $(n=8841)$ had at least one GP or ambulatory care specialist visit within the last 12 months, and of these, around $59 \%$ of participants reported having experienced at least one PSP during this period. Table 1 shows the sociodemographic and socioeconomic parameters of patients affected by PSP $(n=1422)$. About $51 \%$ of the PSP-affected patients were between 40 and 59 years old and $57 \%$ were female. $79.5 \%$ assessed their current health status as (very) good to moderate; around $69 \%$ stated that they had at least one long-term chronic disease at the time of the survey.

\section{Statistical analyses}

The statistical analyses refer to the population that had at least one GP or specialist visit in the 12 months prior to the survey (PSP-1-year-incidence). First, descriptive analyses were carried out. These included, in addition to the
Table 1 Sociodemographic data $(n=1422)$

PAV (\%) $95 \% \mathrm{Cl}$

\begin{tabular}{|c|c|c|c|}
\hline \multirow[t]{2}{*}{$\begin{array}{l}\text { Last GP or } \\
\text { specialist visit* }\end{array}$} & $\begin{array}{l}\text { During the past } 12 \\
\text { months }\end{array}$ & 87.5 & 85.8 to 89.1 \\
\hline & $\begin{array}{l}\text { More than } 12 \\
\text { months ago }\end{array}$ & 12.4 & 11.8 to 13.1 \\
\hline \multirow[t]{2}{*}{ No. of PSP† } & One PSP & 58.8 & 56.2 to 61.3 \\
\hline & More than one PSP & 41.2 & 38.7 to 43.8 \\
\hline \multirow[t]{2}{*}{ Gender } & Male & 43.0 & 40.4 to 45.6 \\
\hline & Female & 57.0 & 54.4 to 59.5 \\
\hline \multirow[t]{3}{*}{ Age groups } & 40-59 years old & 56.6 & 54.0 to 59.2 \\
\hline & 60-79 years old & 36.4 & 34.0 to 39.0 \\
\hline & $80+$ years old & 6.3 & 5.2 to 7.7 \\
\hline \multirow{5}{*}{$\begin{array}{l}\text { Current health } \\
\text { status }\end{array}$} & Very good & 7.1 & 5.9 to 8.6 \\
\hline & Good & 36.8 & 34.3 to 39.3 \\
\hline & Mediocre & 35.6 & 33.1 to 38.1 \\
\hline & Bad & 15.8 & 14.0 to 17.7 \\
\hline & Very bad & 4.6 & 3.7 to 5.9 \\
\hline \multirow{2}{*}{$\begin{array}{l}\text { Chronic } \\
\text { diseases }\end{array}$} & Yes & 69.3 & 66.8 to 71.6 \\
\hline & No & 30.7 & 28.3 to 33.1 \\
\hline \multirow{2}{*}{$\begin{array}{l}\text { Inpatient } \\
\text { treatment } \\
\text { during the past } \\
12 \text { months }\end{array}$} & Yes & 35.1 & 32.7 to 37.6 \\
\hline & No & 64.9 & 62.4 to 67.4 \\
\hline \multirow[t]{2}{*}{ Citizenship } & German & 78.6 & 76.4 to 80.7 \\
\hline & Non-German & 20.0 & 18.0 to 22.2 \\
\hline \multirow{3}{*}{$\begin{array}{l}\text { Subjective } \\
\text { social status }\end{array}$} & High & 32.3 & 30.0 to 34.8 \\
\hline & Medium & 47.0 & 44.5 to 49.6 \\
\hline & Low & 17.9 & 16.0 to 19.9 \\
\hline
\end{tabular}

*PAV, study population of $\geq 40$-year-olds: 10037 participants. †Number of reported PSP with at least one GP or specialist visit during the past 12 months.

GP, general practitioner; PAV, Patient Safety in Ambulatory Care; PSP, patient safety problems.

descriptive analysis of the types of PSP, the specialist group, the type and severity of harm, the recovery time and the type of additional treatment, as well as the descriptive analysis of the reporting and further reaction behaviour including the $95 \%$ CI. The analyses were carried out with SPSS, V.25 and were cross-checked with the statistical package R, V.3.5.2 (Base Package). Chi-square tests $\left(\chi^{2}\right)$ were used to test the hypotheses of whether there were differences in the reporting and further reaction behaviour associated with the determinants 'treatment area', 'PSP types', 'specialist group', 'type of harm' as well as with the 'severity of harm', 'recovery time' and 'additional treatment'. We assumed a significant value of $<0.05$.

Finally, binary logistic regression analyses were used to examine the relationship between the patients' coping strategy with experienced PSP and the patients' sociodemographic factors. Thereby, the reporting and further reaction behaviour of at least one reported 
PSP was defined as the target variable (dependent variable), 'gender', 'age', 'general state of health', 'chronic diseases', 'last GP and specialist visit', 'inpatient treatment', 'nationality' and the 'subjective social status (SSS)' were defined as influencing variables (independent variables). The OR and $95 \%$ CI were estimated.

\section{Patient and public involvement}

Patients were not actively involved in the development of the research question but participated in guided interviews that were conducted to generate items for the survey instrument. Patients were also involved in the study to pretest the survey instrument and finally participated as interviewees. We presented the study results at the German Coalition for Patient Safety conference 2019 where we explicitly invited patient representatives as discussants.

\section{RESULTS}

\section{Coping with experienced PSP}

One thousand, eight hundred and sixty-four (72\%) of 2589 reported self-experienced PSP were reported back by the affected patient or by relatives (77\%) and $1666(64.3 \%)$ PSP resulted in a further reaction by the patient or their relative $(65 \%)$. Based on possible multiple responses, a total of 2980 reports and 2897 further reactions were received, that is, on average, there was one report and one further reaction per experienced PSP. About $46 \%$ of the PSP were reported back to the physician in charge and $37 \%$ to another GP or specialist. About $31 \%$ were reported to the health insurance company/insurance or to another person/institution. Furthermore, about $38 \%$ of PSP caused the affected patients to lose faith in the physician, $33 \%$ of PSP triggered a complaint to the physician in charge and $26 \%$ of PSPs resulted in a change of the physician (see table 2 ).

\section{Differences in reporting and further reaction behaviour depending on PSP type}

Detailed analyses in table 3 show the distribution of the (a) reporting and (b) further reaction behaviour depending on the 'medical treatment area', the 'GP/specialist', 'PSP with or without harm', as well as the 'severity of harm', 'recovery time' and 'additional treatment'. Thus,

Table 2 Reporting and further reaction behaviour to experienced PSP

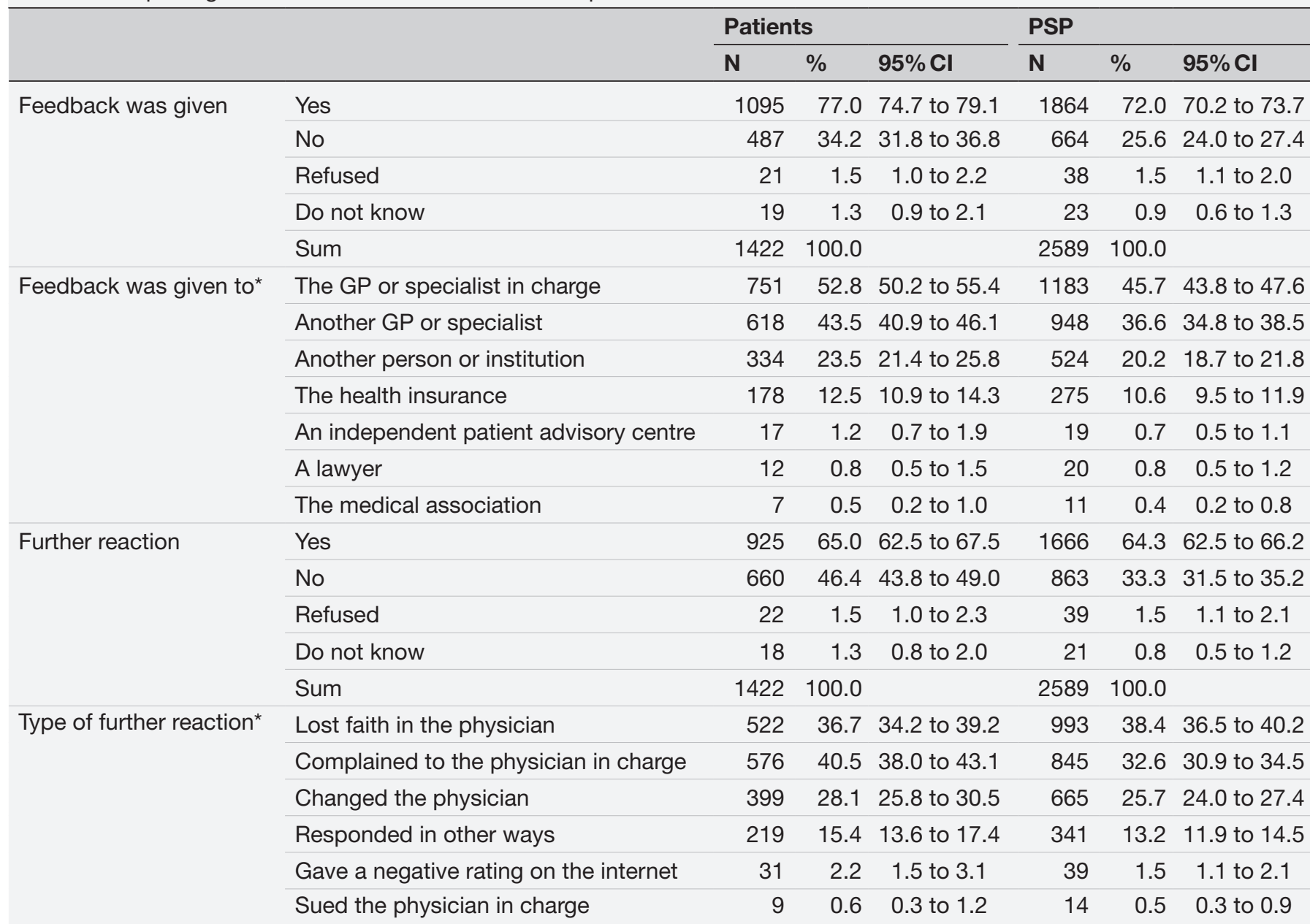

*Multiple answers possible.

GP, general practitioner; PSP, patient safety problems. 
Table 3 Results of $\chi^{2}$ tests to examine whether there were differences in the reporting and further reaction behaviour associated with the determinants 'areas of treatment', 'GP or specialist in charge', 'PSP with/without harm', 'severity of harm', 'recovery time' and 'additional treatments'

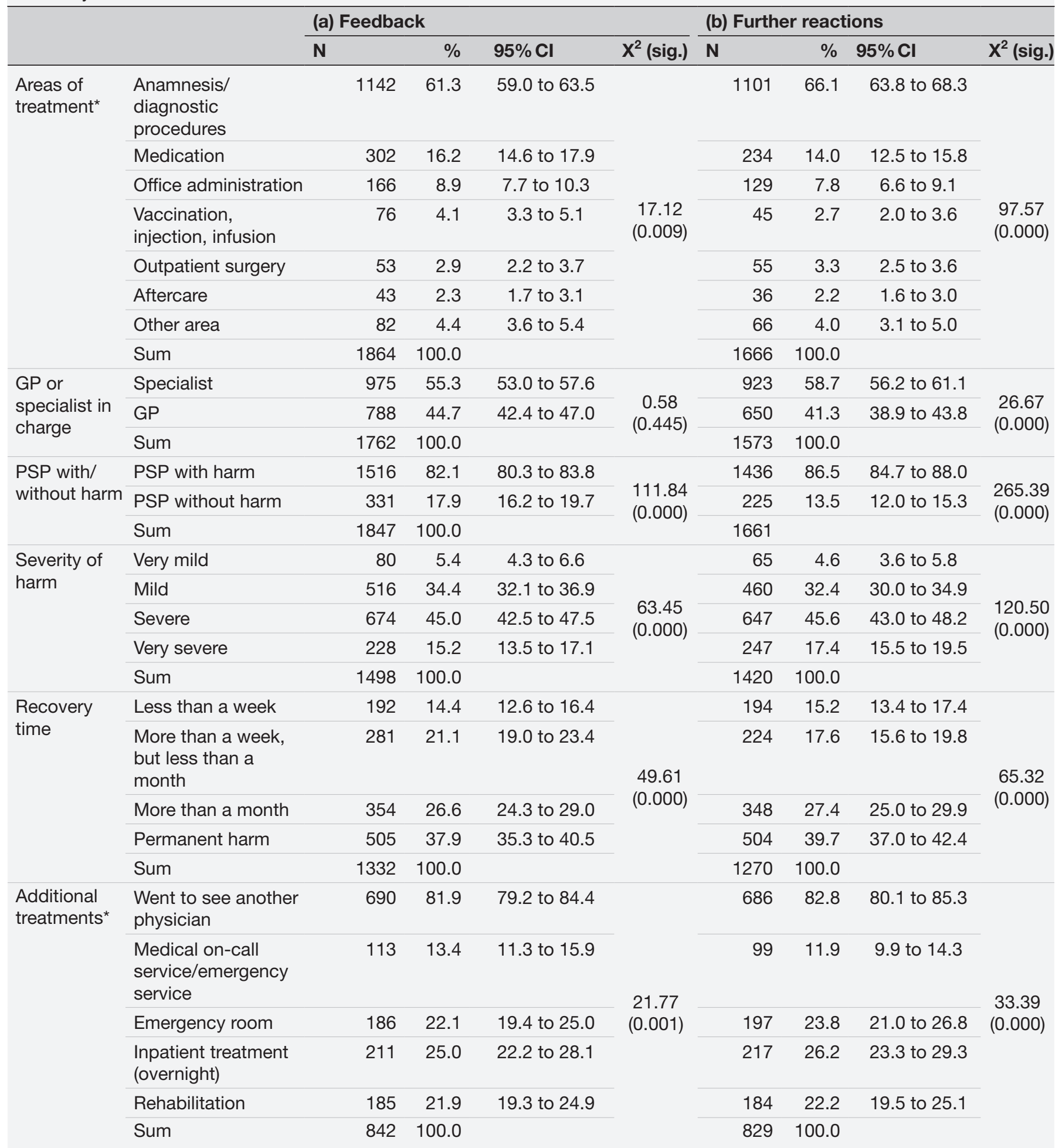

${ }^{*}$ Multiple answers possible.

GP, general practitioner; PSP, patient safety problems.

of the 1864 reports and 1666 further reactions, around $(\mathrm{a})=61 \% /(\mathrm{b})=66 \%$ were in the area of 'anamnesis $/$ diagnostic procedures', (a) $=16 \% /(\mathrm{b})=14 \%$ in the area of 'medication' and around $(a)=9 \% /(b)=7.8 \%$ in the area of 'practice organisation'. More than half of the reports and further reactions occurred when the PSP was experienced by a specialist $((\mathrm{a})=55 \% /(\mathrm{b})=59 \%)$ and was accompanied by harm $((a)=82 \% /(b)=87 \%)$. Except of the 
reporting behaviour to GPs or specialists, significant associations are shown in association with the area of medical treatment ( (a) $\chi^{2}=17.12, \mathrm{p}=0.009 /$ (b) $\chi^{2}=97.57, \mathrm{p}=0.000$ ), PSP with and without harm ( (a) $\chi^{2}=111.84, \mathrm{p}=0.000 /(\mathrm{b})$ $\left.\chi^{2}=265.39, \mathrm{p}=0.000\right)$ and severity $\left(\right.$ (a) $\chi^{2}=63.45, \mathrm{p}=0.000 /$ (b) $\left.\chi^{2}=120.50, \mathrm{p}=0.000\right)$ : the affected patient gave feedback and further reactions significantly more often for PSP related to anamnesis/diagnostic procedures than for PSP related to other types of treatment, for PSP related to specialists than for GPs, for PSP with harm, for more severe harm and longer recovery time. For those who needed further treatment, feedback and further reactions were most likely to occur when the individual needed to see more doctors.

Table 4 shows that of the 1864 reports made, about $70 \%$ were made in the medical treatment area 'anamnesis/ diagnostic procedures' to the physician in charge or to another GP or specialist. Roughly $44 \%$ of the reported PSPs in the mentioned area resulted in a loss of faith in the physician as a further reaction $(\mathrm{n}=1666)$. A similar distribution can be seen in the medical treatment area 'medication'. Here, according to the PSP experienced, about $18 \%$ of the reports were made to the physician in charge or to another GP or specialist. Faith in the physician was lost in about 7\%. Reports to a lawyer, an independent patient counselling centre or the medical association were rather rare (about 3\%). In only about $1 \%$ of the cases were legal steps taken against the physician, especially in the areas of 'anamnesis/diagnostic procedures', 'medication' and 'practice organisation'. Overall, it can be seen that there is a significant association between the addressee of feedback and the type of further reaction and the areas of treatment $\left((\mathrm{a}) \chi^{2}=252.86, \mathrm{p}=0.000\right) /(\mathrm{b})$ $\chi^{2}=241.25, \mathrm{p}=0.000$ ).

A more detailed breakdown of the distribution and significant $\chi^{2}$-analyses by the addressee of reporting and further reaction behaviour and PSP types, specialist groups and harm types are presented in the e-Supplements (online supplemental e-Figure 1 and e-Table 1, 2 ). While there were significant associations between the types of reporting and further reaction behaviour and the PSP types of 'anamnesis/diagnostic procedures' ( (a) $\left.\chi^{2}=145.644, p=0.000 /(b) \chi^{2}=135.616, p=0.000\right)$ and 'medication' ( (a) $\left.\chi^{2}=86.446, \mathrm{p}=0.000\right) /$ (b) $\chi^{2}=46.917$, $\mathrm{p}=0.025)$, there were differences in the PSP of the other medical treatment areas: thus, the analyses do not show any significant associations between the reporting behaviour and the PSP of 'outpatient surgery' and 'aftercare', but between the further reaction behaviour. On the other hand, there is a significant association among the reporting behaviour and the PSP types of 'vaccination, injection, infusion' $\left(\chi^{2}=53.143, \mathrm{p}=0.001\right)$ and 'office administration' $\left(\chi^{2}=69.597, \mathrm{p}=0.000\right)$.

\section{Results of the multiple logistic regression analyses}

As table 5 shows, with the exception of mean SSS, the multivariate regression model yields significant correlations between the sociodemographic characteristics of the participants and the way they deal with experienced PSP. For example, the likelihood of at least one response (a) or one further reaction (b) increases if the ambulatory care patients belong to the youngest group of respondents (40-59years) ((a) OR 2.57/(b) OR 2.60), have had a GP or specialist visit in the last 3 months ((a) OR 2.18/(b) OR 2.17) or have a chronic illness ((a) OR 2.16/(b) OR 2.14). Furthermore, women, those with low SSS, those with recent hospitalisation and poorer selfrated health status were more likely to give feedback or show other responses.

\section{DISCUSSION}

This survey is the first retrospective cross-sectional study to comprehensively assess both PSP in the ambulatory healthcare sector from the patient's perspective, and also its potential impact on the physician-patient relationship. It reports on the reporting and further reaction behaviour of 1422 people from a representative population sample of $10037 \geq 40$-year-olds who experienced a total of 2589 PSP in ambulatory care in Germany in the year prior to the survey and reported them in a CATI survey. One thousand and ninety-five patients (77\%) reported 1864 (72\%) of the PSP back to the healthcare provider or to another healthcare institution. Nine hundred and twenty-five patients $(65 \%)$ reacted in another way to the experienced PSP. In total, there were 1666 (64\%) other reactions in addition to the reports.

The $\chi^{2}$ analyses show significant associations between response and further reaction behaviour and the factors 'treatment area', 'specialist group', 'PSP with/without harm', 'severity', 'recovery time' and 'additional treatment'. More severe harm with specialists requiring further treatment is more likely to be reported back. That there is a relationship between reporting and further reaction behaviour and the factors studied is also confirmed in the $\chi^{2}$ analyses of reporting and further reaction behaviour in association with 'PSP types', 'specialist groups' and 'types of harm'.

In addition, the binary regression analyses suggest that respondents' sociodemographic characteristics influence whether feedback is given or further reactions are shown. Thus, the probability of a response or further reaction increases if the patients are between 40 and 49 years old, have had a GP or specialist visit in the last 3 months and suffer from chronic diseases. Without overinterpreting the results of our survey, a possible reason for these differences may be that those patients with more frequent physician contacts due to chronic illness also have more opportunities to provide feedback and that older patients tend to be more tolerant and lenient with their physicians in charge. Younger patients, on the contrary, complain faster and more strongly. According to the literature review by Kinnunen and Saranto,${ }^{10}$ another reason for the higher willingness to provide feedback by younger patients could be that they are more interested 


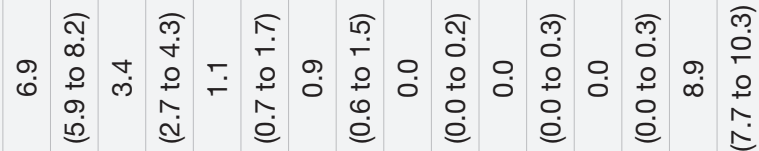

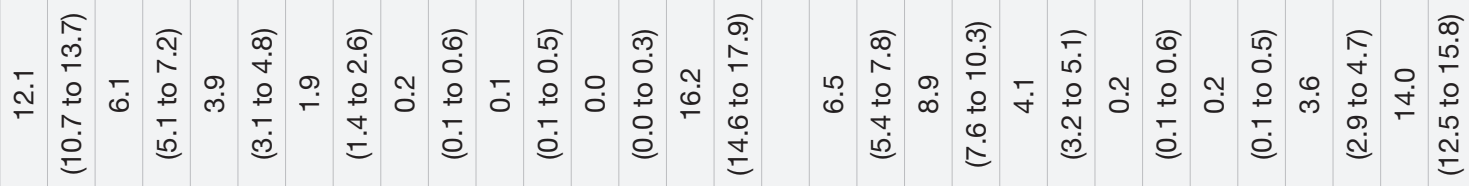

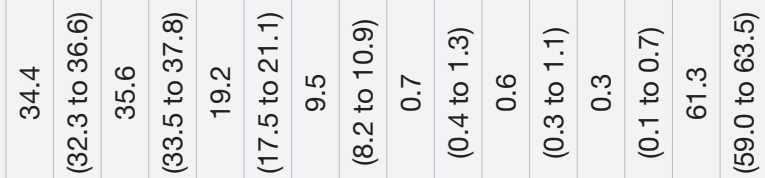

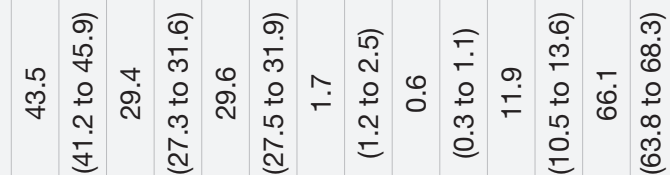

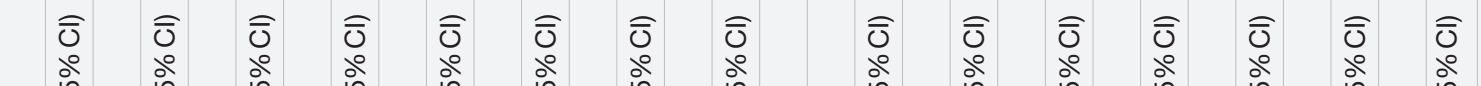

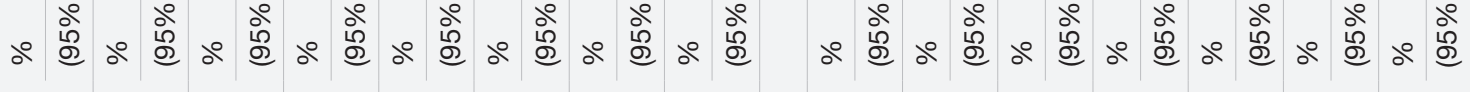

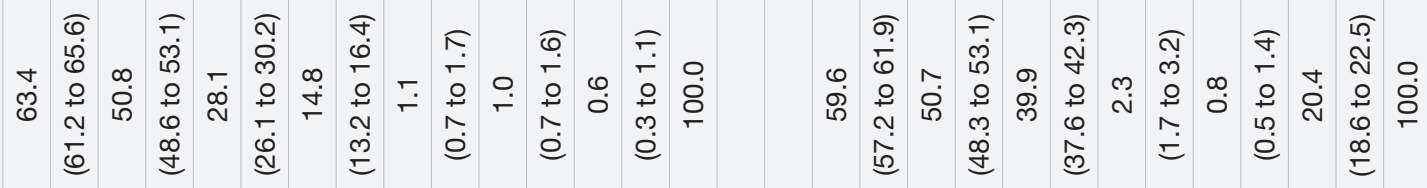

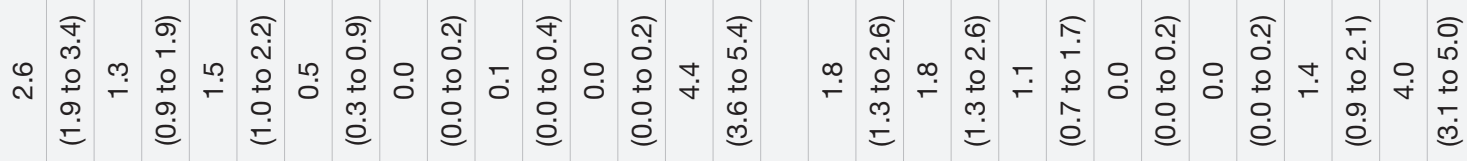

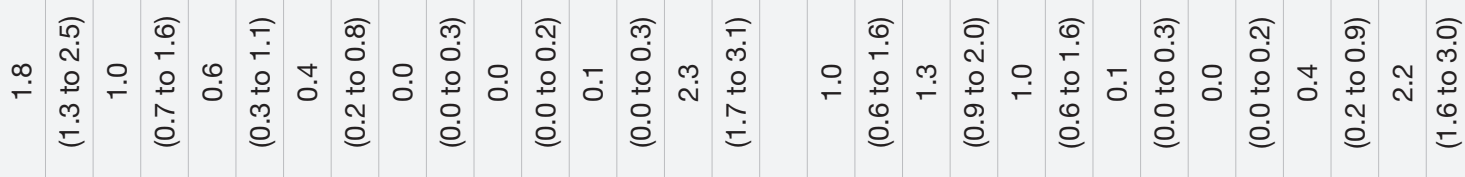

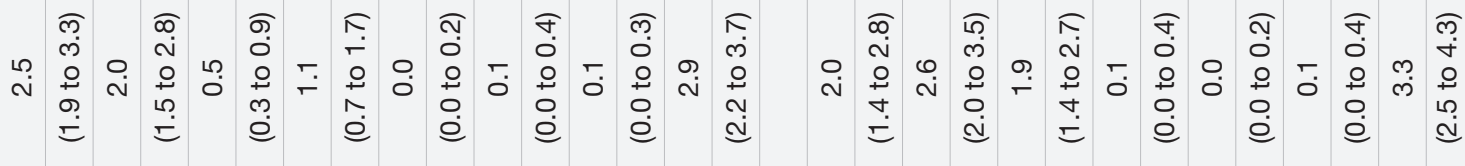

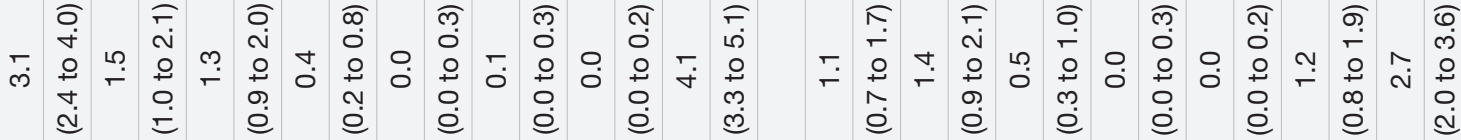

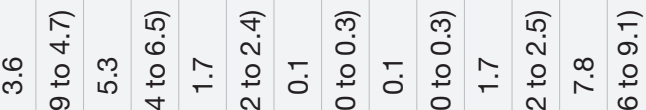

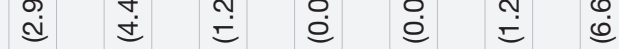
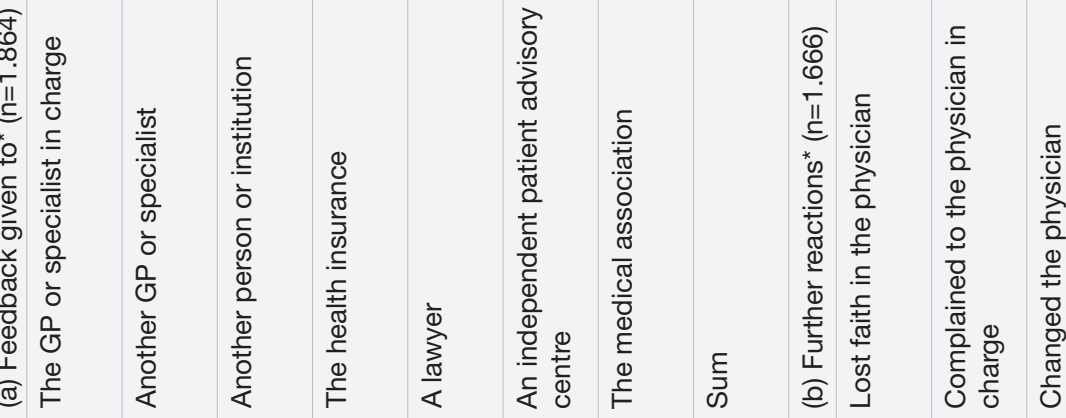
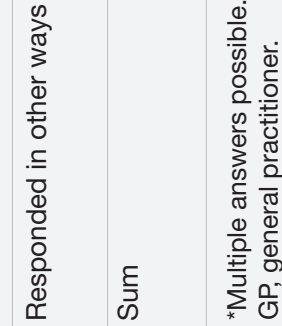
Table 5 Results of binary logistic regression models

\begin{tabular}{|c|c|c|c|c|c|c|}
\hline & \multicolumn{3}{|c|}{ (a) Feedback } & \multicolumn{3}{|c|}{ (b) Further reaction } \\
\hline & OR & $95 \% \mathrm{Cl}$ & Sig. & OR & $95 \% \mathrm{Cl}$ & Sig. \\
\hline Male & 1 & & & 1 & & \\
\hline Female & 1.25 & 1.12 to 1.41 & 0.000 & 1.26 & 1.12 to 1.42 & 0.000 \\
\hline No chronic illnesses & 1 & & & 1 & & \\
\hline Chronic illnesses & 2.16 & 1.89 to 2.47 & 0.000 & 2.14 & 1.87 to 2.46 & 0.000 \\
\hline (Very) good state of health & 1 & & & 1 & & \\
\hline Mediocre state of health & 1.31 & 1.14 to 1.51 & 0.000 & 1.31 & 1.14 to 1.51 & 0.000 \\
\hline (Very) bad state of health & 1.60 & 1.34 to 1.82 & 0.000 & 1.59 & 1.32 to 1.90 & 0.000 \\
\hline Last GP or specialist visit between 4 and 12 months ago & 1 & & & 1 & & \\
\hline Last GP or specialist in the last 3 months & 2.18 & 1.85 to 2.59 & 0.000 & 2.17 & 1.84 to 2.56 & 0.000 \\
\hline No inpatient treatment in the last 12 months & 1 & & & 1 & & \\
\hline Inpatient treatment in the last 12 months & 1.46 & 1.29 to 1.67 & 0.000 & 1.48 & 1.30 to 1.68 & 0.000 \\
\hline$\geq 80+$ years old & 1 & & & 1 & & \\
\hline $60-79$ years old & 1.72 & 1.36 to 2.17 & 0.000 & 1.75 & 1.39 to 2.22 & 0.000 \\
\hline 40-59years old & 2.57 & 2.04 to 3.23 & 0.000 & 2.60 & 2.06 to 3.28 & 0.000 \\
\hline German citizenship & 1 & & & 1 & & \\
\hline No German citizenship & 1.18 & 1.01 to 1.37 & 0.037 & 1.18 & 1.02 to 1.38 & 0.030 \\
\hline High SSS & 1 & & & 1 & & \\
\hline Medium SSS & 0.91 & 0.80 to 1.04 & 0.170 & 0.93 & 0.81 to 1.06 & 0.255 \\
\hline Low SSS & 1.34 & 1.12 to 1.60 & 0.001 & 1.35 & 1.13 to 1.61 & 0.001 \\
\hline
\end{tabular}

in ensuring that PSP are not repeated or that they want to contribute to better research into the causes of PSP.

In comparison with the few (inter)national studies, the reporting and reaction behaviour of patients affected by PSP in Germany exceeds the data reported by Giardina et $a t^{\theta}$ on the reporting behaviour of affected patients $(66 \%)$ as well as the data of the ambulatory physicians surveyed in $2010,38 \%$ of whom stated that they were confronted with allegations of errors at least once a year. ${ }^{6}$ In detail, however, it is also shown that less than $1 \%$ of the PSP led to patients suing the physician in charge according to their own statements and in only about $2 \%$ of the cases did this lead to a negative evaluation on the internet. Regardless, our results indicate that PSPs can have a negative impact on the physician-patient relationship. Thus, about $38 \%$ of the reported PSP resulted in the patients losing their faith in the physician and about $28 \%$ of the patients changed physicians as a result of the experienced PSP. Both, the loss of faith as well as the changing of physicians, are higher in our study compared with similar studies. According to the study by Dovey et $a l^{7}$ $12 \%$ of reported errors led to a loss of trust in the doctor, and according to the studies, ${ }^{11-13} 10 \%-14 \%$ of patients changed their physician as a result of a (suspected) treatment error. Whether there has been an opposite reaction in individual cases due to a PSP in the form of a strengthening of trust between physician and patient, in that patients find that physicians are actively concerned about treating the harm, cannot be assessed on the basis of our study results.

Subsumed, it appears that at least one report and further reaction particularly take place if PSP occur in the medical treatment areas 'anamnesis/diagnostic procedures', 'medication' and 'office administration' and if PSP has been experienced by a specialist, has resulted in mild to severe harm and has led to permanent harm. This can be attributed to the frequency distribution of PSP reports which is-compared with the other factors-particularly higher. It is noteworthy that the treatment area 'anamnesis/diagnostic procedures' accounts for about $70 \%$ of the reports to the physician in charge or to another physician and about $44 \%$ of the further reactions are associated with a loss of faith in the physician, complaints (29\%) or a decision to change the physician (30\%). An explanation for this can be found in previous analyses: ${ }^{1}$ thus, in the area of 'anamnesis/diagnostic procedures', especially the PSP types 'important questions about the complaints not asked' and 'insufficient physical examination' were mentioned, which, according to the respondents, led to severe or even permanent harm. Experience shows that the effect of such PSP can have a negative impact on the physician-patient relationship and can be accompanied by one of the surveyed reporting and further reactions. 


\section{Strength and limitations}

The main strength of the present study is the comprehensive recording of the reporting and further reaction behaviour of patients with PSP reports in ambulatory care. The study allows conclusions to be drawn about the direct effects of PSP in the social interaction between physicians and patients, which are expressed in the fact that patients lose their faith in the physician in charge or change their physician. But, also that patients very often report PSP to their treating doctor or to another GP/ specialist. Furthermore, due to the underlying random sample and high case numbers, the sample is representative for the population of $\geq 40$-year-olds in Germany and sampling errors are relatively small. Hence, a high degree of certainty is provided regarding the coping strategies of patients who have experienced a PSP in ambulatory care. Moreover, the comparison with the last population survey of the RKI, which is responsible for health reporting in Germany, shows that basic health parameters are by and large similar to both study populations. ${ }^{16}$ However, a selection bias in favour of persons with a potentially higher PSP risk (eg, multimorbidity) cannot be precluded with absolute certainty. ${ }^{17}$

However, the study also has weaknesses: 919 (8.3\%) of the respondents dropped out of the interview, which was probably due to the complicated and long questionnaire. In the end, 10192 interviews were realised. Of these, 150 interviews were incomplete because an agreed-upon second appointment could not be realised, and another five interviews could not be evaluated. The response rate ultimately achieved in the target group was $12.4 \%$, which is in the lower range that could be expected.

Another limitation is the chosen method of recording PSP and reporting and reaction behaviour. It deliberately considers only the perspective of patients. A final medical objectification of the experienced PSP as well as a validation of the information on reporting and reaction behaviour is not possible due to the lack of patient records, so that social desirability cannot be ruled out in isolated cases when answering the questions asked. Furthermore, conclusions can be drawn neither from the medical nor from the patient-centred perspective from the present study as to whether the reporting and further reaction behaviour could make a positive contribution to the future avoidance or reduction of PSP or whether it resulted in a satisfactory reaction by the informed GP/ specialist or institution. This is due to the content of the CATI structure, which primarily aimed to ascertain the status quo with regard to the reporting and further reaction behaviour on the part of affected patients. However, our results suggest that patients in ambulatory healthcare are willing to report experienced or suspected PSP to their physicians, whereas it is up to them how they deal with the reports of their patients and how they contextualise them in relation to future care.

A further limitation is that the international transferability of the results is impaired by the fact that the ambulatory care system in Germany takes place much more in the practices of GPs and specialists than is the case in other countries, where specialised care is more hospitalbased. Therefore, the figures from Germany may tend to be higher than in other countries.

\section{Recommendations}

Our study provides evidence for the international call and recommendation, ${ }^{18}{ }^{19}$ for a "cultural drift' ${ }^{20} 21$ using patients increasingly as a valuable source of information in order to gain a better understanding of the occurrence of PSP and thus, to obtain indications for the development of strategies to improve patient safety. Similar to other studies, ${ }^{1822} 23$ we also support the idea to develop systematic and effective feedback and safety monitoring systems which encourages and enables affected patients to report experienced and suspected PSP, but also to share (with regard to individual and general patient safety) their unique perspective and expertise with their GP or specialist in charge. ${ }^{18}$ In this way, the physician-patient relationship can be strengthened and cooperative rather than confrontational communication promoted. ${ }^{24}$ This way enables both the systematic recording of PSP, and also their targeted analysis for a systematic improvement of medical treatment and patient safety in ambulatory healthcare.

Acknowledgements We would like to thank all participants who took part in the study. We would also like to thank Professor N Timmesfeld, University of Bochum, for her statistical support in the study planning. We are grateful to Susann Südhof and Dr Helmut Schröder (infas-Institute of Applied Social Sciences, Bonn) who supervised the CATI survey and its development, as well as Michael Schneider (Philipps-Universität Marburg), who cross-checked data analyses with the statistical package R, V.3.5.2 (Base Package). Finally, we would also like to thank Morgan Scholz for proofreading the manuscript.

Contributors All authors had full access to all of the data (including statistical reports and tables) in the study and take responsibility for the integrity of the data and the accuracy of the data analysis. Study guarantor: MG and WdC. Study concept and design: SS, WdC, JL and MG. Analysis and interpretation of data: SS, WdC, MA, $\mathrm{JL}$ and MG. Drafting of the manuscript: SS. Critical revision of the manuscript for important intellectual content: all authors. Statistical analysis: SS and MA. Study supervision: $\mathrm{MG}$.

Funding This study received funding from the Innovation Committee of the Federal Joint Committee, Germany (grant number 01VSF16015).

Competing interests None declared.

Patient consent for publication Not required.

Ethics approval Ethical approval for the study was obtained through the Ethics Committee of the Philipps-Universität Marburg (AZ 179/17).

Provenance and peer review Not commissioned; externally peer reviewed.

Data availability statement Data are available upon reasonable request. All data relevant to the study are included in the article or uploaded as supplementary information. Deidentified data will be made available after all ongoing analyses are completed. Requesters will be required to sign a Letter of Agreement detailing the mechanisms by which the data will be kept secure and access restricted to their study team. The agreements will also state the recipient will not share the data with anyone outside of their research team.

Supplemental material This content has been supplied by the author(s). It has not been vetted by BMJ Publishing Group Limited (BMJ) and may not have been peer-reviewed. Any opinions or recommendations discussed are solely those of the author(s) and are not endorsed by BMJ. BMJ disclaims all liability and responsibility arising from any reliance placed on the content. Where the content includes any translated material, BMJ does not warrant the accuracy and reliability of the translations (including but not limited to local regulations, clinical guidelines, 
terminology, drug names and drug dosages), and is not responsible for any error and/or omissions arising from translation and adaptation or otherwise.

Open access This is an open access article distributed in accordance with the Creative Commons Attribution Non Commercial (CC BY-NC 4.0) license, which permits others to distribute, remix, adapt, build upon this work non-commercially, and license their derivative works on different terms, provided the original work is properly cited, appropriate credit is given, any changes made indicated, and the use is non-commercial. See: http://creativecommons.org/licenses/by-nc/4.0/.

\section{ORCID iDs}

Svenja Seufert http://orcid.org/0000-0002-3398-2771

Max Geraedts http://orcid.org/0000-0002-5596-6246

\section{REFERENCES}

1 Geraedts M, Krause S, Schneider M, et al. Patient safety in ambulatory care from the patient's perspective: a retrospective, representative telephone survey. BMJ Open 2020;10:e034617.

2 Panesar SS, deSilva D, Carson-Stevens A, et al. How safe is primary care? A systematic review. BMJ Qual Saf 2016;25:544-53.

3 World Health Organization. The conceptual framework for the International classification for patient safety (ICPS). Geneva, 2009.

4 Gallagher TH, Waterman AD, Ebers AG, et al. Patients' and physicians' attitudes regarding the disclosure of medical errors. JAMA 2003;289:1001.

5 Erhard D. Behandlungsfehler gemacht? - So gehst du damit um Arzt im Beruf - via medici. Thieme Via medici. Available: https://www. thieme.de/viamedici/arzt-im-beruf-aerztliches-handeln-1561.htm/ a/umgang-mit-behandlungsfehlern-33318.htm [Accessed 25 Aug 2021].

6 Stiftung Gesundheit. Qualitätsmanagement und Patientensicherheit in Der ärztlichen praxis, 2010

7 Dovey SM, Meyers DS, Phillips RL, et al. A preliminary taxonomy of medical errors in family practice. Qual Saf Health Care 2002;11:233-8.

8 Ushie BA, Salami KK, Jegede AS, et al. Patients' knowledge and perceived reactions to medical errors in a tertiary health facility in Nigeria. Afr Health Sci 2013;13:820-8.

9 Giardina TD, Haskell H, Menon S, et al. Learning from patients experiences related to diagnostic errors is essential for progress in patient safety. Health Aff 2018;37:1821-7.
10 Kinnunen U-M, Saranto K. It is time for self-incident-reporting for patients and their families in every health care organization: a literature review.

11 Mazor KM, Roblin DW, Greene SM, et al. Toward patient-centered cancer care: patient perceptions of problematic events, impact, and response. J Clin Oncol 2012;30:1784-90.

12 Kistler CE, Walter LC, Mitchell CM, et al. Patient perceptions of mistakes in ambulatory care. Arch Intern Med 2010;170:1480-7.

13 Harris L. Public opinion of patient safety issues research findings. Natl Patient Saf Found 1977.

14 STROBE Statement - Checklist of items that should be included in reports of cross-sectional studies. Available: https://www.strobestatement.org/fileadmin/Strobe/uploads/checklists/STROBE_ checklist_v4_cross-sectional.pdf [Accessed 23 Mar 2021].

15 Seufert S, de Cruppé W, Mehl C, et al. [Patient safety in ambulatory care: Development and application of a CATI questionnaire (PSP$\mathrm{AMB}$ ) to capture patient safety problems from the perspective of patients aged 40 years and older]. Z Evid Fortbild Qual Gesundhwes 2021;160:39-47.

16 Robert-Koch-Institut. Beitrag zur Gesundheitsberichterstattung des Bundes - GEDA12. Available: https://www.rki.de/DE/Content/Gesu ndheitsmonitoring/Gesundheitsberichterstattung/GBEDownloadsB/ GEDA12.pdf;jsessionid=F270871E50518320B36CA4ABA58DF80E. 1_cid290?_blob=publicationFile [Accessed 25 Aug 2021].

17 Ricci-Cabello I, Avery AJ, Reeves D, et al. Measuring patient safety in primary care: the development and validation of the "patient reported experiences and outcomes of safety in primary care" (PREOS-PC). Ann Fam Med 2016;14:253-61.

18 Vincent C, Davis R. Patients and families as safety experts. CMAJ 2012;184:15-16.

19 Leatherman S, Berwick DM. Accelerating global improvements in health care quality. JAMA 2020;324:2479.

20 Blumer H. Collective behavior. In: Lee AM, ed. Principles of sociology. New York: Barnes and Noble, 1951: 65-122.

21 Morath J. Changing the healthcare culture: the consumer as part of the system of care. Front Health Serv Manage 2003;19:17-28.

22 Unruh KT, Pratt W. Patients as actors: The patient's role in detecting, preventing, and recovering from medical errors. Int J Med Inform 2007;76:S236-44.

23 Benn J, Koutantji M, Wallace L, et al. Feedback from incident reporting: information and action to improve patient safety. Qual Saf Health Care 2009;18:11-21.

24 Frank S. Patienten als wachsame Partner - Patientenbeteiligung in der Patientensicherheit. Ther Umsch 2012;69:359-62. 